\section{The Operations of Surgery}

Volume I. A. J. Gardham, M.S., F.R.C.S. and D. R. DAvies, M.B., F.R.C.S. Pp. viii +664 with 389 illustrations. London: J. \& A. Churchill. 1963. 100s.

This book retains the original title of W. H. A. Jacobson and its immediate predecessor, edited by R. P. Rowlands and $\mathbf{P}$. Turner and it maintains the same high standard. Produced in the form of two columns to the page with similar clear illustrations Volume I contains information regarding the nonspecialised branches of surgery. As before each section is produced in three parts. First an introduction, concerning the indications for performing various operations. This introduction is compressed into a surprisingly small space and yet contains a large amount of information including physiology, sujgical pathology and a full discussion of controversial points. This clearly reflects the care in editing that has gone into the production of this book. Secondly a section on technique which sets out the steps of an operation and these are well illustrated by line drawings. Where a choice of operation exists the authors leave little doubt as to which they consider to be the safest operation compatible with palliating the patients symptoms. Thirdly a section on after care, with separate chapters on infection and fluid balance. A contribution by $\mathbf{R}$. L. G. Dawson on plastic surgery is a useful addition, particularly as it is based on general surgical principles. The authors explain their reason for including a chapter on anæsthesia.

This book is easily readable and will be of particular value to Registrars and those involved in reading for higher qualifications, and because of its technical detail, as a reference book for the undergraduate. While many books have been published on similar lines this volume is outstanding and the many who enjoyed the old Rowlands and Turner will welcome an up-to-date edition of this work.

\section{Radical Vaginal Hysterectomy}

Schauta-Amreich's Radical Vaginal Operation of Cancer of the Cervix. HANS HögleR, M.D., F.I.C.S. Pp. ix +86 illustrated. Springfield, Illinois: Charles C. Thomas. 1963. 6 dollars 50 cents.

This is an authoritative monograph based on 337 cases describing a simplified surgical technique for the Schauta operation, as performed in Vienna.

It is well produced and the illustrations adequately illustrate the steps of the operation. The English translation is poor, containing many grammatical inaccuracies and errors in spelling, but the descriptions are basically clear.

The recommended indication for the operation is carcinoma of the cervix in stages I and II, a condition for which an abdominal resection is widely preferred in this country. There is no mention of its use in the treatment of carcinoma of the body of the uterus in which it would find greater favour here. None of the patients were treated with preoperative radium which would almost certainly make the operation more hazardous. Dissection of the lymph nodes generally considered an essential part of radical pelvic surgery is impossible by the vaginal route.
Nevertheless, the results are comparable with those treated by more standard methods. A primar mortality of $2.37 \%$ and five years survival cure rate of $76.27 \%$ for stage I and $35.65 \%$ for stage II are claimed. Injury to the rectum, bladder and ureter. were very infrequent and caused no residuoxp disability.

The book should be of use to gynæcologica surgeons learning to master the technique of the operation.

\section{NEW EDITIONS}

\section{An Introduction to Medical Genetics}

J. A. Fraser Roberts. Third edition. Pp. xii 283, illustrated. London: Oxford Universit出 Press. 1963. 35s

The new edition includes additional material of the biochemical aspects of genetics, the genetics of blood grouping and chromosome abnormalities. if reasonably priced book with clear and well-chosen diagrams and illustrations.

\section{Sick Children, Diagnosis and Treatment}

Reginald Lightwood and F. S. W. Brimblea COMBE. 6th edition. Pp. 724 illustratede London: Cassell. 1963. 50s.

One of the best single volume pædiatric manual $\vec{s}$ available. New edition includes chapter on accident in childhood including treatment of poisoning. Detailed and workable index.

\section{Drugs, Medicines and Man}

Harold Burn. Pp. 235. Second edit London: Unwin University Books. 1963. 18s.5 Presents a technical subject to the general publi without losing the essentials which attract the proo fessional reader. Describes the action of a widg range of familiar drugs and includes topics such as alcohol and the motorist, obesity, 'the pill', an the thalidomide disaster.

\section{The Newly Born Infant}

ANDREW Bogdan. Second edition. Pp. 420

Leeds: Austick's Medical Bookshop. 1963. 5s?

A well-conceived book but not entirely suitables for the student as it stands as it contains some. misleading statements.

\section{Diseases of the Liver}

Edited by LEON ScHIFF. Second edition. $x i x+\frac{\text { ? }}{?}$ 916, illustrated. Philadelphia: J. B. Lipincotto

London: Pitman Medical. 1964. £8 8s.

There are now over 30 contributors to this welh known book and new chapters have been added or? ascites, splenic venography and bilirubin metabolism N Contributors from this country include Professon Shelia Sherlock, Dr. Barbara Billing and Professof N. F. Maclagan. A wealth of practical detail is given for the management of ascites and hepatico coma and in the investigatory procedures now neces $\frac{\tau}{D}$ sary in the treatment of liver disease. Highlights? are the description by Drs. Rousselot and Burchelf of their personal experience of 627 splenic veno grams done since 1952, and the review by Dr. DO Seligson of the different but interrelated metabolic processes sited in the liver. 